\title{
Inhibin B and anti-Müllerian hormone/Müllerian- inhibiting substance may contribute to the male bias in autism
}

\author{
MW Pankhurst and IS McLennan
}

The autistic spectrum disorders have a significant male bias in incidence, which is unexplained. The Sertoli cells of the immature testes secrete supra-adult levels of Müllerian-inhibiting substance/anti-Müllerian hormone (AMH) and inhibin B (InhB), with both hormones being putative regulators of brain development. We report here, that 82 boys with an autism spectrum disorder have normal levels of InhB and AMH. However, the boys' level of InhB correlated with their autism diagnostic interview-revised (ADI-R) scores for the social interaction $(R=0.29, P=0.009, N=82)$ and communication domains $(R=0.29, P=0.022, N=63)$, and with the number of autistic traits the boys exhibited $(R=0.34$ and 0.27 , respectively). The strengths of the abovementioned correlates were stronger in the boys with milder autism $(R=0.42$ and 0.50 , respectively), with AMH exhibiting a significant negative correlation to the ADI-R score in these boys $(R=-0.44$ and $R=-0.39$, respectively). Neither hormone correlated to the incidence of stereotyped and repetitive behaviours. This suggests that the male bias in the autistic spectrum has multiple determinants, which modulate the effects of an otherwise non-dimorphic pathology. Furthermore, AMH and InhB have opposing effects on the SMAD1/5/8 pathway, and opposing correlates to autistic traits, implicating the SMAD pathways as a putative point of molecular convergence for the autistic spectrum.

Translational Psychiatry (2012) 2, e148; doi:10.1038/tp.2012.72; published online 14 August 2012

\section{Introduction}

The autistic spectrum is a complex array of disorders involving impairment in the ability to socialise and to communicate, as well as the presence of repetitive or stereotyped behaviours. ${ }^{1}$ Autistic children have accelerated rates of brain growth during infancy, with the size of their brain reverting towards normal during childhood. ${ }^{2}$ Thus, the underlying pathology of autism includes an atypical developmental trajectory.

Autism appears to arise through multiple influences ${ }^{3}$ on a large number of genes, none of which invariably cause an autistic condition. Similarly, few if any of the genes associated with autism are common to all autistic individuals. ${ }^{4-6}$ Hence, the autistic spectrum is likely to have a diverse molecular pathology that converges to produce outcomes that are similar but not identical between individuals.

There is a significant male bias in the incidence of autism. ${ }^{7}$ The genes with known linkage to the autistic spectrum are predominantly autosomal, ${ }^{6,8}$ with no apparent link to sexual dimorphism. This suggests that the male bias in the autistic spectrum may be due to the modulation of a non-dimorphic pathology by sex-specific factors.

The profile of testicular hormones varies during development, with Müllerian-inhibiting substance (anti-Müllerian hormone, $\mathrm{AMH}$ ) and inhibin $\mathrm{B}$ (InhB) being the main secretions for extended periods (Figure 1). AMH triggers the regression of the uterine precursor ${ }^{9}$ and InhB contributes to the control of spermatogenesis in men. ${ }^{10}$ However, the functions of these hormones in male fetuses and boys are only beginning to be examined.

In mice, $\mathrm{AMH}$ establishes some of the sex biases in the nervous system and non-reproductive behaviours. ${ }^{11-13}$ One of the most sexually dimorphic features in children is their rate of maturation, with the brains of boys taking between 2 and 4 years longer to reach peak size than girls. ${ }^{14}$ This sex bias may relate to $\mathrm{AMH}$ and InhB, as a boy's level of these hormones correlate with his developmental trajectory (stature: $\mathrm{AMH}$ and InhB: $:^{15}$ representational drawing: $\mathrm{AMH}$ ). This raises the possibility that these testicular hormones contribute to the male bias in the autistic spectrum. Consistent with this, we report here that the levels of InhB and $\mathrm{AMH}$ in autistic boys correlate with the breadth of their autistic symptoms.

\section{Materials and methods}

Study participants. Blood samples from 98 boys were obtained from the Autism Genetic Resource Exchange (AGRE) biobank (Autism Speaks, USA), and included 82 boys from the autistic spectrum and 16 controls. The diagnosis was determined by the autism diagnostic interview-revised (ADI-R). ${ }^{16}$ Sixty-eight of the autistic spectrum boys had a

Department of Anatomy, Otago School of Medical Sciences, The University of Otago, Dunedin, New Zealand

Correspondence: Professor IS McLennan, Department of Anatomy, Otago School of Medical Sciences, The University of Otago, Lindo Ferguson Building, Great King Street, PO Box 913, Dunedin 9054, New Zealand.

E-mail: ian.mclennan@otago.ac.nz

Keywords: boys; congential disorders; Sertoli cell hormones; sex bias; testes; TGF $\beta$ superfamily

Received 16 March 2012; revised 08 June 2012; accepted 15 June 2012 
diagnosis of autism, eight not-quite autism and six broadspectrum. The AGRE defines not-quite autism as being one point away from the cutoff on one or more domains of the ADI-R. The age range of the autistic participants was 4.4-8.9 years (mean $=6.63 \pm 1.24$ s.d.), whereas the non-autistic boys had a range of $5.1-8.1$ years (mean $=7.13 \pm 1.3$ ). The University of Otago's Human Ethics Committee approved the use of the AGRE samples.

Hormone assays. The levels of hormones were measured using commercial enzyme-linked immunosorbent assay (ELISA), according to the manufacturer's instructions. The assays were conducted in two batches, with four samples being assayed in both batches. The ELISAs were: $A M H$, Beckman Coulter, Brea, CA, USA; A16507 (batch 1) and A79765 (batch 2); InhB, Beckman Coulter, A81303. Assays were conducted in duplicate using serum or plasma samples, with quadratic equations used to calculate sample values from the standard curves. The correlates between the

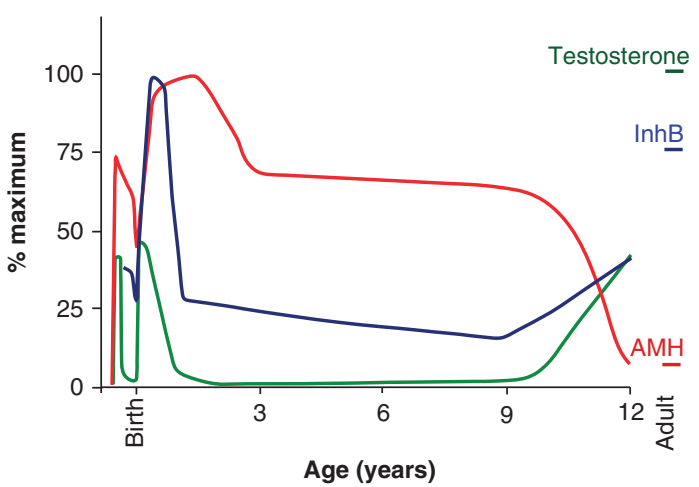

Figure 1 The pattern of testicular hormones varies during development. The diversity of autistic symptoms suggests that the autistic spectrum arises from multiple influences on multiple cellular processes within the brain, occurring at various times. The figure illustrates the pattern of testicular hormones during male development. Note that the Sertoli cell hormones (AMH: red line, InhB: dark blue line) have a wider temporal influence than testosterone: green line. Each hormone is dimorphic, with the female levels illustrated in Supplementary Figure S1. The levels of AMH are supra-adult throughout development, as is $\operatorname{lnhB}$ during part of the first year. The figure is based on multiple sources including (refs. 15, 21, 36-41). hormones and ADI-R were similar for both batches. The absolute values for the AMH ELISAs showed good agreement between the batches. The data from second batch of InhB ELISAs were $20 \%$ higher in both the four cross-batch samples and the mean, and a correction factor was therefore applied. No significant difference was observed between plasma or serum samples for the mean concentrations of either hormone (data not shown).

Statistical analysis. Statistical calculations were undertaken with PASWstatistics18.0. (SPSS Inc, IBM, Armonk, NY, USA). The mean differences between the autistic and non-autistic boys were examined by Student's $t$-test and by a generalised linear model including age and condition. The relationships between $\mathrm{AMH}$ and InhB and a boy's ADI-R score were examined by linear regression, with the partial correlates and the Pearson correlates recorded.

The three ADI-R domains (social development and play; communication; repetitive or restricted behaviours) and their associated subdomains were separately analysed. Nineteen of the autistic spectrum boys were non-verbal, and therefore lacked scores for the non-verbal subdomains (COM2T_CS and COM3T_CS). This reduced the sample size to 63 for these subdomains and for the communication domain. The cohort was also stratified by the boy's ADI-R score for the social development and play domain, in order to compare boys with mild and more severe symptoms.

The number of symptoms for each domain was calculated by adding the number of subdomains with scores of 1,2 or 3 . The average severity of a boy's symptoms was the mean score of subdomains with a score of 1,2 and 3.

\section{Results}

Autism has been postulated to be an extreme male phenotype. ${ }^{17}$ We therefore examined whether autistic boys have abnormal levels of Sertoli cell hormones. Eighty-two boys with diverse autistic symptoms and sixteen age-matched controls were examined using blood samples from the AGRE biobank. The levels of InhB and AMH in the autistic boys were similar to those of the non-autistic boys, as was the ratio of the two hormones (Figure 2).
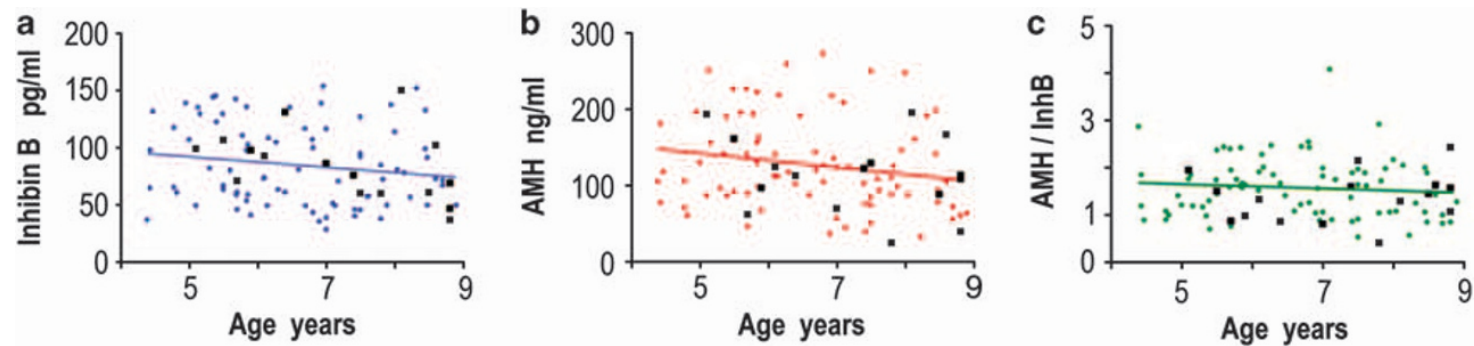

Figure 2 The levels of Sertoli cell hormones are similar in autistic and non-autistic boys. (a) InhB, (b) AMH and (c) the ratio between AMH and InhB, expressed in arbitrary units. The values for non-autistic boys are shown as black squares $(n=16)$, with the data from autistic boys being illustrated in coloured circles $(n=82)$. The correlation of the hormones to the age of the autistic spectrum boys was: $\operatorname{lnhB} r=-0.17, P=0.14 ; \mathrm{AMH} r=-0.19, P=0.09$ and $\mathrm{AMH} / \mathrm{InhB} r=-0.09, P=0.41 ; n=82$. The trend for a slight decrease in InhB and AMH with age has been previously observed, and is statistically significant in some studies. ${ }^{15}$ Age was therefore included in subsequent regression analyses. The levels of hormones were not significantly different (Student's $t$-test, and general linear model, to account for any effect of the age) between the autistic (InhB 99.8 $\pm 44.9 ; \mathrm{AMH}, 127.5 \pm 59.7$ ) and non-autistic boys (InhB 84.1 $\pm 30.2 ; \mathrm{AMH}, 113.3 \pm 50.0)$. 
We then examined whether a boy's level of Sertoli cell hormones affected the severity of his symptoms, and/or the probability of him being diagnosed with an autistic trait. The boy's level of InhB correlated with their ADI-R score for both the social interaction and communication and language domains, but not for the repetitive and stereotypic behaviour domain (Figure 3). There was no clear association between $\mathrm{AMH}$ and the ADI-R domains (Supplementary Figure S2).

The three ADI-R domains are each composed of four subdomains. The 12 subdomains are largely but not totally independent, with the average pairwise correlation coefficient between them being $14 \pm 2 \%$ (range $0-41 \%$, median $11 \%$, Supplementary Table S1). InhB positively correlated $(R>0.2)$ with 8 of the 12 subdomains, 7 of which were in the social interaction and communication and language domains (Table 1). Five of these correlations were statistically significant, with the other three having $P$ values between 0.05 and 0.08 (Table 1). This indicates that InhB has a broad but moderate association across the breadth of the social and communication domains, rather than a strong effect on a few traits. The boy's AMH levels were not significantly associated with any of the subdomains. However, all of the subdomains with stronger associations to InhB exhibited moderate negative correlates to $\mathrm{AMH}$ (Table 1).

The scores for each subdomain have multiple components and a high score can be due to a greater number of autistic traits and/or a greater severity of traits. InhB positively correlated with the number of symptoms in both the social interaction $(R=0.34, P=0.002)$ and the communication and language domain $(R=0.27, P=0.035)$, but not with the average severity of the traits (Table 2). As with the total score, there was a non-significant trend for $\mathrm{AMH}$ to negatively correlate with the number of symptoms whenever InhB was positively correlated with the symptom (Table 2).

The association of InhB with the number of symptoms indicates that a boy's level of hormone relates to the clinical discrimination between the absence and presence of an autistic trait. This suggests that the Sertoli cell hormones may have a greater effect when the underlying pathology is less severe. Consistent with this, InhB correlated more strongly with the milder cases than with the boys who had more severe symptoms (Table 2). The correlate was with the number of
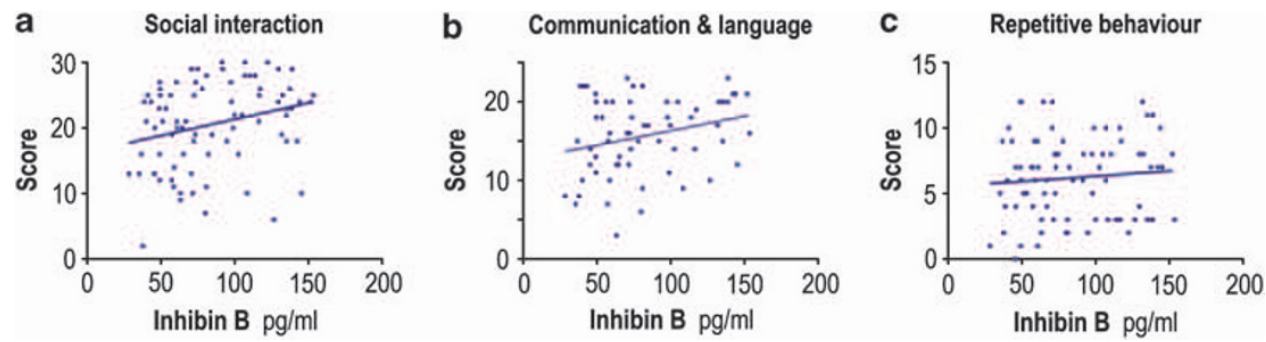

Figure 3 A boy's level of InhB correlates with two of his ADI-R scores. The boy's level of InhB was measured by ELISA and correlated with the scores for each of the three ADI-R domains. The level of InhB positively correlated with the boy's social score (a) $R=0.26, P=0.017, n=82$ and his communication and language score (b) $R=0.27$, $P=0.035, n=63$, but not with his repetitive and stereotypic behaviour score (c) $R=0.09, n=82$.

Table 1 Relationship between the ADI-R domains and the boy's age and levels of Sertoli cell hormones

\begin{tabular}{|c|c|c|c|c|c|c|c|c|}
\hline \multirow[t]{2}{*}{ Domain/subdomain } & \multirow[t]{2}{*}{ Code } & \multirow[t]{2}{*}{$\#$} & \multicolumn{2}{|c|}{$\operatorname{lnh} B$} & \multicolumn{2}{|c|}{$\boldsymbol{A M H}$} & \multicolumn{2}{|c|}{ Age } \\
\hline & & & $\mathbf{R}$ & $\mathbf{P}$ & $\mathbf{R}$ & $\mathbf{P}$ & $\mathbf{R}$ & $\mathbf{P}$ \\
\hline $\begin{array}{l}\text { Social interaction } \\
\text { Failure to use nonverbal behaviours to regulate social interaction } \\
\text { Failure to develop peer relationships } \\
\text { Lack of shared enjoyment } \\
\text { Lack of socioemotional reciprocity }\end{array}$ & $\begin{array}{l}\text { SOCT_CS } \\
\text { SOC1T_CS } \\
\text { SOC2T_CS } \\
\text { SOC3T_CS } \\
\text { SOC4T_CS }\end{array}$ & $\begin{array}{l}82 \\
82 \\
82 \\
82 \\
82\end{array}$ & $\begin{array}{l}0.29 \\
0.20 \\
0.22 \\
0.25 \\
0.27\end{array}$ & $\begin{array}{l}0.009 \\
0.079 \\
0.047 \\
0.028 \\
\mathbf{0 . 0 1 4}\end{array}$ & $\begin{array}{r}-0.13 \\
0.05 \\
-0.10 \\
-0.16 \\
-0.17\end{array}$ & & $\begin{array}{l}0.09 \\
0.27 \\
0.00 \\
0.07 \\
0.01\end{array}$ & 0.014 \\
\hline $\begin{array}{l}\text { Communication and language } \\
\text { Lack or delay in spoken language and failure to compensate through gesture } \\
\text { Relative failure to initiate or sustain conversational interchange } \\
\text { Stereotyped, repetitive or idiosyncratic speech } \\
\text { Lack of varied spontaneous make-believe or social imitative play }\end{array}$ & $\begin{array}{l}\text { COMVT_CS } \\
\text { COM1T_CS } \\
\text { COM2T_CS } \\
\text { COM3T_CS } \\
\text { COM4T_CS }\end{array}$ & $\begin{array}{l}63 \\
82 \\
63 \\
63 \\
82\end{array}$ & $\begin{array}{r}0.29 \\
0.28 \\
0.24 \\
-0.12 \\
0.27\end{array}$ & $\begin{array}{l}0.022 \\
0.013 \\
0.062 \\
0.014\end{array}$ & $\begin{array}{l}-0.14 \\
-0.12 \\
-0.03 \\
-0.03 \\
-0.16\end{array}$ & & $\begin{array}{r}0.07 \\
0.00 \\
-0.21 \\
0.17 \\
0.14\end{array}$ & \\
\hline $\begin{array}{l}\text { Repetitive and stereotypic behaviour } \\
\text { Encompassing preoccupation or circumscribed pattern of interest } \\
\text { Apparently compulsive adherence to nonfunctional routines or rituals } \\
\text { Stereotyped and repetitive motor mannerisms } \\
\text { Preoccupation with part objects or non-functional elements of materials }\end{array}$ & $\begin{array}{l}\text { BEHT_CS } \\
\text { BEH1T_CS } \\
\text { BEH2T_CS } \\
\text { BEH3T_CS } \\
\text { BEH4T_CS }\end{array}$ & $\begin{array}{l}82 \\
82 \\
82 \\
82 \\
82\end{array}$ & $\begin{array}{r}0.02 \\
-0.08 \\
0.01 \\
0.20 \\
0.00\end{array}$ & 0.071 & $\begin{array}{r}0.06 \\
0.09 \\
-0.02 \\
-0.06 \\
0.19\end{array}$ & 0.093 & $\begin{array}{r}-0.07 \\
-0.09 \\
-0.08 \\
-0.04 \\
0.06\end{array}$ & \\
\hline
\end{tabular}

Abbreviations: AMH, anti-Müllerian hormone; InhB, inhibin B. The score for each domain was correlated with the boy's InhB, AMH and age using a linear regression model, and the partial correlates recorded. Positive correlates of $>0.1$ are indicated in green and negative correlates in red. The $P$ values of $<0.1$ are recorded, with significant results indicated in bold. COM2T_CS and COM3T_CS are not applicable for non-verbal autistic individuals, and the number of participants is therefore lower for these subdomains and the COMVT__CS domain. 
Table 2 Relationship between the number and severity of autistic symptoms and a boy's levels of hormones

\begin{tabular}{|c|c|c|c|c|c|c|c|c|c|c|c|c|c|}
\hline \multirow[t]{3}{*}{ Domain } & \multirow[t]{3}{*}{$\#$} & \multicolumn{6}{|c|}{$\operatorname{lnh} B$} & \multicolumn{6}{|c|}{$A M H$} \\
\hline & & \multicolumn{2}{|c|}{ Total score } & \multicolumn{2}{|c|}{ \# of traits } & \multicolumn{2}{|c|}{ Ave severity } & \multicolumn{2}{|c|}{ Total score } & \multicolumn{2}{|c|}{ \# of traits } & \multicolumn{2}{|c|}{ Ave severity } \\
\hline & & $\mathbf{R}$ & $\mathbf{P}$ & $\mathbf{R}$ & $\mathbf{P}$ & $\mathbf{R}$ & $\mathbf{P}$ & $\mathbf{R}$ & $\mathbf{P}$ & $\mathbf{R}$ & $\mathbf{P}$ & $\mathbf{R}$ & $\mathbf{P}$ \\
\hline $\begin{array}{c}\text { Entire cohort } \\
\text { SOCT_CS } \\
\text { COMT_CS } \\
\text { BEHT_CS }\end{array}$ & $\begin{array}{l}82 \\
63 \\
82\end{array}$ & $\begin{array}{l}0.29 \\
0.29 \\
0.02\end{array}$ & $\begin{array}{l}0.009 \\
0.022\end{array}$ & $\begin{array}{r}0.34 \\
0.27 \\
-0.01\end{array}$ & $\begin{array}{l}0.002 \\
0.035\end{array}$ & $\begin{array}{l}0.11 \\
0.04 \\
0.01\end{array}$ & & $\begin{array}{r}-0.13 \\
-0.14 \\
0.06\end{array}$ & & $\begin{array}{r}-0.19 \\
-0.16 \\
0.06\end{array}$ & & $\begin{array}{r}-0.04 \\
-0.05 \\
0.12\end{array}$ & \\
\hline $\begin{array}{l}\text { Mild cases } \\
\text { SOCT_CS } \\
\text { COMT_CS } \\
\text { BEHT_CS }\end{array}$ & $\begin{array}{l}31 \\
31 \\
30\end{array}$ & $\begin{array}{l}\mathbf{0 . 4 2} \\
0.50 \\
0.30\end{array}$ & $\begin{array}{l}0.022 \\
0.007\end{array}$ & $\begin{array}{l}0.46 \\
0.41 \\
0.29\end{array}$ & $\begin{array}{l}0.012 \\
0.030\end{array}$ & $\begin{array}{r}0.04 \\
-0.02 \\
0.21\end{array}$ & & $\begin{array}{l}-0.44 \\
-0.39 \\
-0.13\end{array}$ & $\begin{array}{l}0.018 \\
0.039\end{array}$ & $\begin{array}{l}-\mathbf{0 . 4 6} \\
-0.33 \\
-0.10\end{array}$ & $\begin{array}{l}\mathbf{0 . 0 1 2} \\
0.090\end{array}$ & $\begin{array}{r}-0.25 \\
-0.12 \\
0.00\end{array}$ & 0.090 \\
\hline $\begin{array}{c}\text { More severe c } \\
\text { SOCT_CS } \\
\text { COMT_CS } \\
\text { BEHT_CS }\end{array}$ & $\begin{array}{l}\text { ses } \\
51 \\
51 \\
52\end{array}$ & $\begin{array}{r}0.26 \\
0.05 \\
-0.13\end{array}$ & & $\begin{array}{r}0.36 \\
0.04 \\
-0.19\end{array}$ & 0.010 & $\begin{array}{l}-0.01 \\
-0.09 \\
-0.14\end{array}$ & & $\begin{array}{r}-0.15 \\
-0.03 \\
0.08\end{array}$ & & $\begin{array}{r}-0.29 \\
-0.09 \\
0.09\end{array}$ & 0.044 & $\begin{array}{l}0.01 \\
0.16 \\
0.18\end{array}$ & \\
\hline
\end{tabular}

Abbreviations: $\mathrm{AMH}$, anti-Müllerian hormone; InhB, inhibin B. The boys with an autistic spectrum disorder were stratified into mild (SOCT_CS <20) and more severe cases. The boys' score for each domain was then correlated with their levels of InhB, AMH and age using a linear regression model, and the partial correlates recorded. Positive correlates of $>0.1$ are indicated in green and negative correlates in red. The $P$ values of $<0.1$ are recorded, with significant results indicated in bold. The severity of traits are classified on a 1 to 3 scale by the clinicians assessing the boys, with the scores of 3 (severe autism) being recoded to 2 to generate the computer scores (_CS) used for diagnosis. The 'average severity' was calculated using the initial scores of 1-3. Scores of 0 (no definitive behaviour of the type specified) were not included in the average. The 'number of traits' is the number of the traits coded as 1,2 or 3.

Table 3 Calculated effect of Inhibin B on the autistic scores of boys

\begin{tabular}{lcccc}
\hline ADI-R domain & \multirow{2}{*}{$\begin{array}{c}\text { ADI- } \boldsymbol{R} \\
\text { Cutoff }\end{array}$} & \multicolumn{3}{c}{ Inhibin B } \\
\cline { 3 - 5 } & & Minima & Median & Maxima \\
\hline Social interaction & 10 & 15.6 & 18.9 & 24.7 \\
Communication and language & 8 & 13.0 & 15.7 & 20.3 \\
Repetitive and stereotypic & 3 & 6.8 & 6.9 & 7.1 \\
behaviour & & & &
\end{tabular}

Abbreviation: ADI-R, autism diagnostic interview-revised. The relationship between a boy's InhB and ADI-R scores were calculated from the formulae generated from the regression analysis (Table 1 ). The ADI-R cutoff is the minimum score required for the diagnosis of autistic spectrum disorder.

autistic traits and the total score for each domain, but not with the average severity of the traits (Table 2).

When the mild and severe groups were separately analysed, the negative association between $\mathrm{AMH}$ and the ADI-R scores was strong, consistent and statistically significant, whenever InhB positively correlated to a trait (Table 2). For the social interaction domain, the relationship between $\mathrm{AMH}$ and the total score of the mild group was $R=-0.44, P=0.018$. In the mild group, boys with higher levels of $\mathrm{AMH}$ exhibited fewer symptoms $(R=-0.46, P=0.012)$.

A semi-quantitative estimate of the potential importance of the hormones can be obtained from the regression curves. With the autistic spectrum disorders as a whole, the effect of reducing a boy's level of InhB from the maxima to the minima of the natural range would on average decrease his social interaction score by 9.1 and his communication and language score by 7.3 (Table 3 ).

\section{Discussion}

The autistic spectrum disorders have a strong male bias, but are not male-specific. This suggests that the initiation of the underlying pathology involves a non-dimorphic mechanism, with the male bias resulting from modulation of the pathogenic pathway by sex-specific signals. Consistent with this, the levels of Sertoli cell hormones in boys with an autistic spectrum disorder correlated with the breadth of their autistic traits, but not with a uniform direction. The positive correlation between InhB and autistic traits was consistently stronger than the negative correlation between $\mathrm{AMH}$ and autistic traits. If these correlates indicate causality, then the net effect of the Sertoli cell hormones would be to exacerbate autistic pathology in most males, but with the extent of the exacerbation being affected by the balance between $\mathrm{AMH}$ and InhB.

Neither InhB nor AMH correlated with the boy's repetitive and stereotypic behaviours, even though the incidence of these traits has a male bias. Consequently, the Sertoli cell hormones are unlikely to be the sole male influence on the autistic spectrum. This is broadly consistent with the emerging view that the male phenotype is generated by multiple hormones and various genetic mechanisms, arising from the sex chromosomes. ${ }^{18}$

The levels of $\mathrm{AMH}$ and InhB in the boys with an autism spectrum disorder were similar to the control group (Figure 2), and to previous studies of boys recruited from the community ${ }^{15}$ (see also Lee et al. ${ }^{19}$, Andersson et al. ${ }^{20}$ and Aksglaede et $\left.a l^{21}\right)$. Consequently, a boy's level of $\mathrm{AMH}$ and InhB is insufficient to cause an autistic condition, in the absence of other influences. The autism spectrum disorders are postulated to be an extreme variant of the male brain, secondary to extreme levels of hormones. ${ }^{17}$ In this study, the autistic boys did not have extreme levels of Sertoli cell hormones.

Both $\mathrm{AMH}$ and InhB are plausible modulators of autistic pathology. Brain development is very extended, and unlike testosterone, $\mathrm{AMH}$ and $\mathrm{InhB}$ are present in male blood throughout the entire period of brain development (Figure 1). Furthermore, as noted in the Introduction, children with an 
autism spectrum disorder have an altered developmental trajectory, ${ }^{2}$ with $\mathrm{AMH}$ and InhB being recently identified as putative male-specific determinants of the speed of development. $^{15}$

Complex traits emerge through the interaction of large number of genetic and other determinants. For this to occur, the various influences must converge onto a small number of final pathways. For example, the growth hormone $(\mathrm{GH}) /$ insulin-like growth factor (IGF) axis has a central role in growth, even though the $G H$ and IGF genes are not significant genetic determinants of height. ${ }^{22}$ The $\mathrm{GH} / \mathrm{IGF}$ axis is important because many of the determinants of height exert their influence by altering the levels of $\mathrm{GH}$ and/or IGF1. The influence of $\mathrm{GH} / \mathrm{IGF}$ on height is therefore large compared with any of the primary determinants of height, because it integrates multiple influences.

$\mathrm{AMH}$ and InhB may be points of conversion for the modulation of autistic traits. Neither hormone is a known genetic determinant of autism spectrum disorders. The coefficients of determination $\left(R^{2}\right)$ from the observed correlates indicate that the combined effect of $\mathrm{AMH}$ and InhB accounted for approximately $20 \%$ of the variation in the number of autistic traits in mild cases of male autism and about $7 \%$ of the variance across the autism spectrum as a whole. This is similar to the influence of $\mathrm{GH} / \mathrm{IGF}$ on the variation in height between similar-aged boys ${ }^{15}$ and is very large relative to the influence of various genetic determinants of autism. ${ }^{4-6}$

InhB and $\mathrm{AMH}$ are members of the large TGF $\beta$ superfamily (Figure 4), whose actions are predominantly channelled through two intracellular pathways, SMAD1,5,8 and SMAD2,3. ${ }^{23-25}$ InhB and $\mathrm{AMH}$ have opposing effects on autistic symptoms (Table 3 ), and on the activation of the SMAD1,5,8 pathway (Figure 4). This implicates the SMAD1,5,8 pathway as a potential site of convergence for the autistic spectrum, with low activation of this pathway being predicted to lead to a poor prognosis. The SMAD1,5,8 pathway has multiple sexually dimorphic and non-dimorphic activators (Figure 4). Consequently, this putative point of convergence may be relevant to both males and females with autism spectrum disorder.

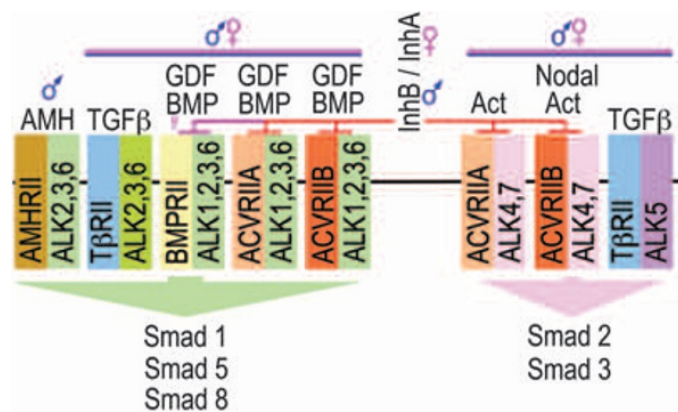

Figure 4 Signaling by the TGF $\beta$ superfamily. In humans, the superfamily has 33 members, consisting of 3 TGF $\beta$ s, 21 BMP/GDFs, 8 Activins/inhibins and AMH. The family share 5 type II receptors and 7 type I receptors, which lead to the activation of either the Smad 1/5/8 or the Smad 2/3 pathway. The activated Smads are transported to the nucleus, where they regulate transcription. Various binding proteins, such as betaglycan, modulate the specificity of the signaling (reviewed in David et al. ${ }^{23}$, Lowery and de Caestecker ${ }^{24}$ and Santibanez et al. ${ }^{25}$ ).
The various autistic traits are not strongly concordant (Supplementary Table S1), indicating that the autistic spectrum has multiple points of convergence. InhB, but not $\mathrm{AMH}$, also affects activation of the SMAD2,3 pathway, ${ }^{23-25}$ and we do not discount the possibility that this pathway contributes to autistic pathology.

All stages of brain development are regulated by the TGF $\beta$ superfamily, as is the mature function of the brain. The SMAD pathways are thus plausible determinants of autistic pathogenesis. The receptors for $\mathrm{AMH}$ are present on most neurons, and $\mathrm{AMH}$ contributes to the sex biases in the brain. ${ }^{11-13,15}$ InhB is a negative regulator of signalling (Figure 4), and its effects on the brain have been rarely studied. This is surprising, given that the receptors it modulates are broadly expressed in the brain ${ }^{26-28}$ and regulate the proliferation, differentiation, migration, survival and mature ${ }^{29,30}$ function $^{28}$ of neurons. ${ }^{31}$ Similarly, astrocyte and oligodendrocyte glial lineages are also regulated through the SMAD pathways. ${ }^{32,33}$

The current study is a cross-sectional analysis of hormone levels in boys whose autistic symptoms have already developed. The validity and statistical power of this approach is dependant on two characteristics of the hormones. First, the levels of $\mathrm{AMH}$ and InhB in boys are highly variable compared with other hormones, this variation being essential for the generation of statistical power. ${ }^{15,21}$ Second, the differences between boys are relatively stable: neither hormone varies with time of day, from day-to-day or from season-to-season, in contrast to the regulation of these hormones in adults. ${ }^{15,21,34,35}$ Consequently, the rank order of boys based on their hormone levels varies little from year to year ${ }^{15}$ (see also Aksglaede et al. $^{21}$ ). Variation in rank order for hormones during development would be expected to degrade the correlation between hormones and traits. The current study may therefore be a conservative estimate of the influence of InhB and $\mathrm{AMH}$ on the breadth of autistic symptoms.

This study has also several inherent limitations; the most obvious being that it does not establish causality, or identify when the Sertoli cell hormones may act during development. If the relationship is causal, the data also does not establish whether InhB and AMH effect the development of autistic traits or vice versa. Furthermore, the complexity of the autistic spectrum means that correlative analyses have more power to detect some influences than others. These limitations are discussed in greater detail in the Supplementary Information. We emphasise that the significance of the reported data is that it gives rise to a novel hypothesis that needs to be tested by interventional studies and various other correlative investigations, including longitudinal studies of at-risk male babies to determine whether their levels of $\mathrm{AMH}$ and InhB early in development is predictive of the breadth of autistic traits later in life.

In summary, the reported observations suggest that the male bias in autism arise from multiple factors, with both InhB and $\mathrm{AMH}$ being putative influences. They also point to the TGF $\beta$ superfamily as being points of convergence for autistic influences. In addition, the data support the notion that sex differences in disorders can arise through the interaction between sex-specific biology and a non-dimorphic pathology. When this is occurring, the influence of the sex-specific factor should be evident in a correlative study, but may not be 
evident when the mean levels of the factor are compared between the study and control group.

\section{Conflict of interest}

The authors declare no conflict of interest.

Acknowledgements. This study was funded by a New Economic Research Fund grant from the Ministry of Science and Innovation, New Zealand. We thank Ms N Batchelor and B-L Leathart for their technical assistance, and Prof. $\mathrm{P}$ Herbison for his statistical advice. We gratefully acknowledge the resources provided by the AGRE consortium and the participating AGRE families. The AGRE is a programme of Autism Speaks and is supported, in part, by grant 1U24MH081810 from the National Institute of Mental Health to CM Lajonchere (PI).

1. Levy SE, Mandell DS, Schultz RT. Autism. Lancet 2009; 374: 1627-1638.

2. Courchesne E, Campbell K, Solso S. Brain growth across the life span in autism: age-specific changes in anatomical pathology. Brain Res 2010; 1380: 138-145.

3. Newschaffer CJ, Croen LA, Daniels J, Giarelli E, Grether JK, Levy SE et al. The epidemiology of autism spectrum disorders. Annu Rev Public Health 2007; 28 : 235-258.

4. Sebat J, Lakshmi B, Malhotra D, Troge J, Lese-Martin C, Walsh T et al. Strong association of de novo copy number mutations with autism. Science 2007; 316: 445-449.

5. Pinto D, Pagnamenta AT, Klei L, Anney R, Merico D, Regan R et al. Functional impact of global rare copy number variation in autism spectrum disorders. Nature 2010; 466: $368-372$

6. Geschwind DH. Genetics of autism spectrum disorders. Trends Cogn Sci 2011; 15 409-416.

7. Fombonne E. Epidemiological surveys of autism and other pervasive developmental disorders: an update. J Autism Dev Dis 2003; 33: 365-382.

8. Abrahams BS, Geschwind DH. Advances in autism genetics: on the threshold of a new neurobiology. Nat Rev Genet 2008; 9: 341-355.

9. MacLaughlin DT, Donahoe PK. Sex determination and differentiation. New Eng J Med 2004; 350: 367-378

10. de Kretser DM, Buzzard JJ, Okuma Y, O'Connor AE, Hayashi T, Lin SY et al. The role of activin, follistatin and inhibin in testicular physiology. Mol Cell Endocrinol 2004; 225: 57-64.

11. Morgan K, Meredith J, Kuo J-YA, Bilkey DK, McLennan IS. The sex bias in novelty preference of preadolescent mouse pups may require testicular Müllerian inhibiting substance. Behav Brain Res 2011; 221: 304-306.

12. Wang PY, Koishi K, McGeachie AB, Kimber M, Maclaughlin DT, Donahoe PK et al. Mullerian inhibiting substance acts as a motor neuron survival factor in vitro. Proc Natl Acad Sci USA 2005; 102: 16421-16425.

13. Wang PY, Protheroe A, Clarkson AN, Imhoff F, Koishi K, McLennan IS. Müllerian Inhibiting Substance contributes to sex-linked biases in the brain and behavior. Proc Natl Acad Sci USA 2009; 106: 7203-7208.

14. Giedd JN, Rapoport JL. Structural MRI of pediatric brain development: what have we learned and where are we going? Neuron 2010; 67: 728-734.

15. Morgan K, Dennis NA, Ruffman T, Bilkey DK, McLennan IS. The stature of boys is inversely correlated to the levels of their Sertoli cell hormones: do the testes restrain the maturation of boys? PLoS One 2011; 6: e20533.

16. Lord C, Rutter M, Le Couteur A. Autism diagnostic interview-revised: a revised version of a diagnostic interview for caregivers of individuals with possible pervasive developmental disorders. J Autism Dev Dis 1994; 24: 659-685.

17. Baron-Cohen S. The extreme male brain theory of autism. Trends Cogn Sci 2002; 6 248-254.

18. Arnold A. Sex chromosomes and brain gender. Nat Rev Neurosci 2004; 5: 701-708.

19. Lee MM, Donahoe PK, Hasegawa T, Silverman B, Crist GB, Best S et al. Mullerian inhibiting substance in humans: normal levels from infancy to adulthood. J Clin Endocrinol Metab 1996; 81: 571-576.

20. Andersson AM, Juul A, Petersen JH, Muller J, Groome NP, Skakkebaek NE. Serum inhibin $B$ in healthy pubertal and adolescent boys: relation to age, stage of puberty, and follicle-

stimulating hormone, luteinizing hormone, testosterone, and estradiol levels. J Clin Endocrinol Metab 1997; 82: 3976-3981.

21. Aksglaede L, Sorensen K, Boas M, Mouritsen A, Hagen CP, Jensen RB et al. Changes in anti-Mullerian hormone (AMH) throughout the life span: a population-based study of 1027 healthy males from birth (cord blood) to the age of 69 years. J Clin Endocrinol Metab 2010; 95: 5357-5364.

22. Lango Allen H, Estrada K, Lettre G, Berndt SI, Weedon MN, Rivadeneira F et al. Hundreds of variants clustered in genomic loci and biological pathways affect human height. Nature 2010; 467: 832-838.

23. David L, Feige JJ, Bailly S. Emerging role of bone morphogenetic proteins in angiogenesis. Cytokine Growth Factor Rev 2009; 20: 203-212.

24. Lowery JW, de Caestecker MP. BMP signaling in vascular development and disease. Cytokine Growth Factor Rev 2010; 21: 287-298.

25. Santibanez JF, Quintanilla M, Bernabeu C. TGF-beta/TGF-beta receptor system and its role in physiological and pathological conditions. Clin Sci 2011; 121: 233-251.

26. Cameron VA, Nishimura E, Mathews LS, Lewis KA, Sawchenko PE, Vale WW. Hybridization histochemical localization of activin receptor subtypes in rat brain, pituitary, ovary, and testis. Endocrinology 1994; 134: 799-808.

27. Soderstrom S, Bengtsson H, Ebendal T. Expression of serine/threonine kinase receptors including the bone morphogenetic factor type II receptor in the developing and adult rat brain. Cell Tissue Res 1996; 286: 269-279.

28. Shoji-Kasai Y, Ageta H, Hasegawa Y, Tsuchida K, Sugino H, Inokuchi K. Activin increases the number of synaptic contacts and the length of dendritic spine necks by modulating spinal actin dynamics. J Cell Sci 2007; 120: 3830-3837.

29. Ebendal T, Bengtsson $\mathrm{H}$, Soderstrom S. Bone morphogenetic proteins and their receptors potential functions in the brain. J Neurosci Res 1998; 51: 139-146.

30. Sanchez-Camacho C, Bovolenta P. Emerging mechanisms in morphogen-mediated axon guidance. Bioessays 2009; 31: 1013-1025.

31. Liu A, Niswander LA. Bone morphogenetic protein signalling and vertebrate nervous system development. Nat Rev Neurosci 2005; 6: 945-954.

32. Stipursky J, Gomes FC. TGF-beta1/SMAD signaling induces astrocyte fate commitment in vitro: implications for radial glia development. Glia 2007; 55: 1023-1033.

33. Bilican B, Fiore-Heriche C, Compston A, Allen ND, Chandran S. Induction of Olig2 precursors by FGF involves BMP signalling blockade at the Smad level. PLoS One 2008; 3 : e2863.

34. Crofton PM, Evans AE, Wallace AM, Groome NP, Kelnar CJ. Nocturnal secretory dynamics of inhibin $\mathrm{B}$ and testosterone in pre- and peripubertal boys. J Clin Endocrinol Metab 2004; 89: 867-874.

35. Dennis NA, Houghton LA, Jones GT, van Rij AM, Morgan K, McLennan IS. The level of serum anti-mullerian hormone correlates with vitamin $D$ status in men and women but not in boys. J Clin Endocrinol Metab 2012; 97: 2450-2455.

36. Guibourdenche J, Lucidarme N, Chevenne D, Rigal O, Nicolas M, Luton D et al. AntiMullerian hormone levels in serum from human foetuses and children: pattern and clinical interest. Mol Cell Endocrinol 2003; 211: 55-63.

37. Morpurgoa PS, Cetinb I, Borgatoa S, Cortelazzia D, Nobile-DeSantisb MS, Vaghia I et al. Circulating levels of inhibin $A$, inhibin $B$ and activin $A$ in normal and intrauterine growth restricted (IUGR) fetuses. Eur J Obst Gyn Reprod Biol 2004; 117: 38-44.

38. Bergada I, Milani C, Bedecarras P, Andreone L, Ropelato MG, Gottlieb S et al. Time course of the serum gonadotropin surge, inhibins, and anti-Mullerian hormone in normal newborn males during the first month of life. J Clin Endocrinol Metab 2006; 91: 4092-4098.

39. Wudy SA, Dorr HG, Solleder C, Djalali M, Homoki J. Profiling steroid hormones in amniotic fluid of midpregnancy by routine stable isotope dilution/gas chromatography-mass spectrometry: reference values and concentraions in fetuses at risk for 21-hydroxylase deficiency. J Clin Endo Metab 1999; 84: 2724-2728.

40. Wudy SA, Wachter UA, Homoki J, Teller WM. 17alpha-hydroxyprogesterone 4-androstenedione and testosterone profiled by routine stable isotope dlution/gas chromatography-mass spectrometry of children. Ped Res 1995; 38: 76-80.

41. Takagi S, Yoshida T, Tsubata K, Ozaki H, Fujii TK, Nomura Y et al. Sex differences in fetal gonadotropins and androgens. J Steroid Biochem 1977; 8: 609-620.

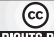

OMERTEHI

published by Nature Publishing Group. This work is licensed under the Creative Commons Attribution-Noncommercial-No Derivative Works 3.0 Unported License. To view a copy of this license, visit http://creativecommons.org/licenses/by-nc-nd/3.0/

\section{Supplementary Information accompanies the paper on the Translational Psychiatry website (http://www.nature.com/tp)}

